\title{
Depression, Anxiety and Alcohol Abuse in a Gastroenterology Intensive Care Unit: Prevalence and Detection
}

\author{
Graça Cardoso ${ }^{1,2, *}$, Joana Alexandre ${ }^{1}$ and Alda Rosa ${ }^{3}$ \\ ${ }^{1}$ Serviço de Psiquiatria, Hospital Fernando Fonseca, 2720-276 Amadora, Portugal \\ ${ }^{2}$ CEDOC, Departamento de Saúde Mental, Faculdade de Ciências Médicas, FCM, Universidade Nova de Lisboa, 1169 - \\ 056 Lisboa, Portugal \\ ${ }^{3}$ Centro de Atendimento de Toxicodepentes (CAT), 2560-649 Torres Vedras, Portugal
}

\begin{abstract}
:
Objectives: To assess depression, anxiety, and alcohol abuse in a Gastroenterology ICU, and the level of its detection by the staff.

Method: All patients consecutively admitted to the ICU during a six-month period, 18 or above, and staying $\geq 24$ hours, were assessed with the Hospital Anxiety and Depression Scale (HADS) and the CAGE. Doctors and nurses assessed the type and severity of patients' morbidity. Data were analyzed with Student's t-test, Pearson's and Spearman's correlations for ordinal variables, chi-square for nominal variables, and multiple logistic regression.

Results: The 65 patients assessed had a mean age of 57, and were predominantly male (58.5\%), married (72.3\%), and retired $(53.8 \%) ; 27.7 \%$ had a psychiatric history, $24.6 \%$ were on psychotropic drugs, and $32.3 \%$ had an alcohol intake above standards. Anxiety and depression HADS scores $\geq 8$ were present in $29.2 \%$ and $35.4 \%$ of the patients, respectively; $20 \%$, mainly men, scored positive on the CAGE. Women had significantly higher anxiety scores (=.012) than men but did not differ in depression. A psychiatric history was significantly associated with higher anxiety $(\mathrm{p}<.001)$ and depression $(\mathrm{p}=.007)$ scores, as well as being on psychotropic drugs regularly $(\mathrm{p}<.001 ; \mathrm{p}=.03$, respectively).

Doctors diagnosed somatic illness in $48.8 \%$, and somatic illness with psychiatric co-morbidity in $51 \%$; for nurses the rates were, respectively, $41.5 \%$ and $58.6 \%$. Doctors' and nurses' detection of psychiatric disorders were significantly associated with the HADS anxiety scores $(\mathrm{p}=.013 ; \mathrm{p}=.001$, respectively), and doctor's detection with depression ( $\mathrm{p}=.046)$ scores. There were no significant associations between nurses' detection of psychiatric disorders and depression, and between both professional groups detection and alcohol abuse.

Conclusion: High prevalence of depression, anxiety, and alcohol abuse in Gastroenterology ICU was confirmed. However, the level of detection by the staff was low and mainly when anxiety symptoms were present.
\end{abstract}

Key Words: Depression, anxiety, alcohol abuse, detection, ICU.

\section{INTRODUCTION}

The prevalence of psychiatric morbidity in general hospital inpatients has been described as very high [1] varying between 21 and $40 \%$ [2, 3]. A large percentage of these patients suffer from diagnosable psychiatric disorders, frequently triggered by hospital admission, which can be related or not to the somatic condition. Patients admitted to an Intensive Care Unit (ICU) are more at risk for psychiatric comorbidity, due to the severity of somatic illness, as well as to pharmacological and environmental factors, and will probably present higher rates of psychiatric symptoms. Rincon $e t$ al. [4] found that $29.2 \%$ of the adult patients in ICU screened positive in at least one of the following scales: anxiety, depression, delirium, and drinking problems.

\footnotetext{
*Address correspondence to this author at the Serviço de Psiquiatria, Hospital Fernando Fonseca, 2720-276 Amadora, Portugal; Tel: +351 21434 8272; Fax: +351 21434 5566; E-mails: gracacardoso@gmail.com, joanaalexandre@gmail.com, alda_rosa@hotmail.com
}

Delirium is a frequent complication in ICU, and the prevalence reported in medical and surgical ICU cohort studies varies from 40 to $80 \%$, depending upon the severity of illness and methods of diagnosis [5,6].

Depression and anxiety disorders and symptoms are frequent in ICU, and not uncommonly associated with cognitive dysfunction. They may precede or be part of delirium. In the Rincon et al. study [4], the prevalence rates were $13.7 \%$ for depression and $24 \%$ for anxiety.

Depressive and anxiety symptoms can persist several months after discharge. The prevalence of clinically significant depressive symptoms in patients 2 months after discharge from ICU was 33\% [7], and depression and anxiety symptom rates, measured with the Hospital Anxiety and Depression Scale (HADS), were as high as $47 \%$ and $24 \%$ respectively, 9 months after discharge from ICU [8].

Substance abuse or dependence, being a risk factor for severe somatic illness, is frequently present in ICU patients. 
Alcohol consumption increases the risk of intensive care admission and of hospital death in men [9], and is directly related to the admission in 21 to $28 \%$ of ICU patients $[10,11,12]$. Drinking problems have been reported in $37.9 \%$ of ICU patients [4], and alcohol-related conditions described in 44 to $51 \%$ of gastroenterology inpatients $[13,14]$. This could point to a higher prevalence rate of alcohol abuse in gastroenterology ICUs compared to general ICUs, that has not been addressed in previous studies. On the other hand, in general ICUs there is great variety of severe somatic illnesses, with respiratory, cardiovascular, traumatic conditions, and suicide attempts, while in a gastroenterology ICU there is a more homogeneous somatically ill population.

Despite the high rates of psychiatric co-morbidity, less than $5 \%$ of general hospital inpatients are referred to psychiatry [3]. Since the presence of psychiatric morbidity is associated with worse prognosis and increased mortality in patients with somatic illness, $[15,16]$ there is a great need to promote and improve the level of detection by general hospital staff.

To our knowledge, there are no published studies on assessment of depression, anxiety and alcohol abuse prevalence rates and detection in gastroenterology intensive care units. The current study had two main hypotheses: 1) the rates of psychiatric morbidity in a gastroenterology ICU differ from those in general ICUs; 2) the levels of detection by doctors and nurses in this setting are low to moderate.

\section{AIMS}

The objectives of this study were to assess the level of depressive and anxiety symptoms, and of alcohol abuse in patients admitted to a gastroenterology intensive care unit, and to establish the level of detection of psychiatric morbidity by ICU doctors and nurses.

\section{METHODS}

\section{Sample}

All the patients consecutively admitted to the Gastroenterology Intensive Care Unit (GE ICU) of Hospital Santa Maria, a university general hospital in Lisbon, between February and July 1995, and with no cognitive impairment of sufficient severity to preclude a standardized assessment, were included in the study. Length of ICU stay shorter than 24 hours and being under 18 years of age were considered exclusion criteria.

\section{Description of the Unit}

The unit is part of the Gastroenterology Department, and only admits patients with severe gastroenterological conditions. It consists of a large room with ten beds, separated by curtains, and of a smaller room with 2 beds for patients with more severe conditions.

\section{Procedures}

The patients were interviewed during the first 72 hours of admission to the unit by one of the authors (A.R.), and assessed with the HADS [17], a self-report Likert scale that includes two subscales, for depressive and anxiety symptoms, with 7 questions each, rating from 0 to 3 , and a total score range between 0 and 21 , a higher score being more symptomatic. A cut off of 8 in any of the subscales was used in the study.

The patients were also assessed with the CAGE [18], a self-report 4 question yes/no scale aimed at assessing alcohol dependence, and positive when at least one question is answered yes.

The following variables were collected during hospital stay: age, gender, marital and professional status, level of education, living situation, somatic diagnoses, psychiatric history, being on psychotropic drugs, level of alcohol intake, number of days in the unit, and type of discharge. The patients were considered to have an alcohol intake above standard levels if it was at least $80 \mathrm{~g}$ per day for males, and $40 \mathrm{~g}$ per day for females. Psychological distress was operationalised as a total score of the HADS equal or above 16 (the sum of the subscales cut-off).

Doctors and nurses of the GE ICU were asked to fill a questionnaire aimed at assessing their patients as being somatic only, somatic with psychiatric morbidity, or psychiatric with somatic comorbity and the condition severity in a linear scale from 1 to 5 , in which 1 represented minimum and 5 highest possible severity. They were also asked to formulate a diagnosis of the psychiatric morbidity, when present.

The study was submitted to the Hospital Santa Maria Ethics and Research Committee, and was approved without restrictions. All the patients gave their oral informed consent after reading the study description, and having their questions answered.

Statistical analysis was performed using the program SPSS, version 14. The sample's characteristics were described with descriptive measures such as mean, standard deviation, percentages and range. Student's t-test and, when appropriate, Mann-Whitney test were used for quantitative variables, and Spearman and Pearson's correlations for ordinal variables. Chi-square and Fisher's exact test (whenever chi-square assumptions were not met) were calculated for nominal variables. To assess the effect of past variables on current psychological distress and its detection by physicians and nurses, multiple logistic regression was carried out.

\section{Results}

During the inclusion period, 168 consecutive patients were admitted to the GE ICU, of which 68 were excluded on the grounds of staying in the unit less than 24 hours $(n=67)$, and being under $18(n=1)$. Seventeen patients could not be interviewed during the first 72 hours, and further 17 patients could not be assessed due to severe cognitive impairment during the first 72 hours of admission.

The group of 65 patients that met the inclusion criteria and were assessed with the HADS and the CAGE (as shown on Table 1) had a mean age of 57 years, and the majority were men $(59 \%)$, married $(72 \%)$, retired $(54 \%)$, living with their family $(89 \%)$, and with less than 4 years of education $(51 \%)$. Most of the patients $(72 \%)$ had never been treated for emotional problems, and were not currently taking psychotropic drugs (75\%). The main reason for admission was gastrointestinal bleeding in 39 patients $(60 \%)-38.5 \%$ of the total sample due to peptic ulcer and $21.5 \%$ to esophageal 
Table 1. Demographic and Clinical Characteristics of the Sample $(\mathbf{n}=65)$

\begin{tabular}{|c|c|}
\hline Age yrs, $x \pm s d$ [range] & $57.2 \pm 15.8(20-92)$ \\
\hline \multirow{3}{*}{$\begin{array}{c}\text { Gender }(\%) \\
\text { Male } \\
\text { Female }\end{array}$} & \\
\hline & $38(58.5)$ \\
\hline & $27(41.5)$ \\
\hline \multicolumn{2}{|l|}{ Marital status (\%) } \\
\hline Married & $47(72.3)$ \\
\hline Single & $8(12.3)$ \\
\hline Widower & $7(10.8)$ \\
\hline Divorced/separated & $3(4.6)$ \\
\hline Professional status (\%) & $35(24.5)$ \\
\hline Retired & $35(53.9)$ \\
\hline Active & $26(40.0)$ \\
\hline Unemployed & $3(4.6)$ \\
\hline On sick leave & $1(1.5)$ \\
\hline \multicolumn{2}{|l|}{ Education $(\%)$} \\
\hline Illiterate & $17(26.2)$ \\
\hline No formal education & $16(24.5)$ \\
\hline Basic education & $25(38.5)$ \\
\hline High school & $4(6.2)$ \\
\hline College & $3(4.6)$ \\
\hline \multicolumn{2}{|l|}{ Living conditions (\%) } \\
\hline With family & $58(89.2)$ \\
\hline Alone & $6(9.3)$ \\
\hline Other & $1(1.5)$ \\
\hline \multicolumn{2}{|l|}{ Main reason for admission (\%) } \\
\hline Gastrointestinal bleeding & $39(60.0)$ \\
\hline Pancreatitis & $14(21.5)$ \\
\hline Other & $12(18.5)$ \\
\hline Alcohol intake above standards (\%) & $21(32.3)$ \\
\hline Psychiatric history (\%) & $18(27.7)$ \\
\hline On psychotropic drugs (\%) & $16(24.6)$ \\
\hline Length of ICU stay (days), $\mathrm{x} \pm \mathrm{sd}$ [range] & $7.2 \pm 4.0[3-24]$ \\
\hline Outcome (\%) & \\
\hline Transferred to medical ward & $35(53.8)$ \\
\hline Death & $2(3.1)$ \\
\hline Other & $28(43.1)$ \\
\hline
\end{tabular}

varices - followed by pancreatitis $(21.5 \%)$. The mean length of stay in the unit was 7 days, and more than half of the patients were transferred to a medical ward (54\%), while $3 \%$ died while in Intensive Care.

The CAGE and HADS scores are shown on Table 2. Thirteen patients $(20 \%)$ were considered positive with the CAGE. The HADS mean anxiety score was $6.2 \pm 4.0$, and the mean depression score was 6.2 \pm 4.8 . Nineteen patients (29.2\%) had a score above the cut off $(\geq 8)$ in the HADS anxiety subscale, and $23(35.4 \%)$ in the depression subscale.

Table 2. Assessment with the Hospital Anxiety and Depression Scale and the CAGE $(n=65)$

\begin{tabular}{|c|c|}
\hline CAGE $-\mathrm{n}(\%)$ & \\
Negative (scoring 0) & $52(80)$ \\
Positive (scoring at least 1) & $13(20)$ \\
\hline HADS - Depression, mean (sd) & $6.2(4.8)$ \\
HADS - Depression $\geq 8, \mathrm{n}(\%)$ & $23(35.4)$ \\
\hline HADS - Anxiety, mean (sd) & $6.2(4.0)$ \\
HADS - Anxiety $\geq 8, \mathrm{n}(\%)$ & $19(29.2)$ \\
\hline
\end{tabular}

Tables 3 to $\mathbf{5}$ show the relationship between demographic and clinical variables and the scales' scores, as well as between the HADS and the CAGE scores, using Student's ttest, chi-square, Fisher's exact test and Pearson's correlation.

Women had significantly higher mean anxiety scores on the HADS than men (7.7 vs. 5.2, $\mathrm{p}=.012)$, but the two genders did not differ on the HADS mean depression scores. Higher anxiety and depression scores on the HADS were significantly associated with past psychiatric history (10.0 vs. $4.7, \mathrm{p}<.001$ for anxiety; 9.6 vs. $5.1, \mathrm{p}<.001$ for depression), and use of psychotropic drugs (8.7 vs. 5.2, $\mathrm{p}=.007$ for anxiety; 8.4 vs. $5.5, \mathrm{p}=.030$ for depression). Alcohol intake above standard was significantly associated with higher depression scores (8.6 vs. 5.1, $\mathrm{p}=.005)$, but not with anxiety scores. A significant positive correlation between anxiety and depression scores on the HADS (Pearson' $\mathrm{s}=.582 ; \mathrm{p}<$ .001) was found. Depression or anxiety HADS scores were not significantly correlated with being CAGE positive.

Multiple logistic regression, considering psychological distress (HADS total score at least 16) as dependent variable and having as main independent variables the use of psychotropic drugs and psychiatric history, showed that the main variable, current use of psychotropic medication, had an Odds Ratio (OR) of 2.3 (95\% Confidence Interval (CI): 0.33 - 16.43; $\mathrm{p}=.398$ ) but no statistical effect on psychological distress, while psychiatric history obtained an OR of 7.4 (95\% CI: 1.14 - 47.55; $\mathrm{p}=.036$ ) and a significant effect on psychological distress.

There was a statistically significant correlation between the CAGE scores and gender, with $31.6 \%$ of men rating positive vs. $3.7 \%$ of women, $\mathrm{p}=.01$. On the other hand, $52.4 \%$ of the inpatients scoring positive on the CAGE had an alcohol intake above standard vs. $4.5 \%$ of those with consumption below standard $(\mathrm{p}<.001)$. The sensitivity and specificity of the CAGE test for the detection of alcohol intake above $80 \mathrm{~g}$ for men and $40 \mathrm{~g}$ for women in this sample were $52 \%$ and $95 \%$, respectively.

\section{Detection of Psychiatric Co-Morbidity by ICU Staff}

Results of ICU doctors' and nurses' detection of somatic and psychiatric disorders in their patients are shown on Table 6. Twenty patients were not evaluated by the doctors and 24 by the nurses. 
Table 3. Demographic and Clinical Characteristics of the CAGE Positive and Negative Cases (n=65)

\begin{tabular}{|c|c|c|c|}
\hline CAGE & Positive & Negative & Statistical Analysis \\
\hline Gender ( $\%$ males / females) & $31.6 / 3.7$ & $68.4 / 96.3$ & Fisher's; $\mathrm{p}=.010^{*}$ \\
\hline Marital status ( $\%$ married / other) & $19.1 / 22.2$ & $80.9 / 77.8$ & Fisher's; $p=.743^{*}$ \\
\hline Employment (\% active / other) & $15.4 / 23.1$ & $84.6 / 76.9$ & Fisher's; $\mathrm{p}=.538^{*}$ \\
\hline Psychotropic drugs (\%Y / N) & $12.5 / 22.4$ & $87.5 / 77.6$ & Fisher's; $p=.492 *$ \\
\hline Alcohol intake (\%Y / N) & $52.4 / 4.5$ & $47.6 / 95.5$ & Fisher's; $p<.001 *$ \\
\hline
\end{tabular}

* Fisher's exact test; ** Student's t-test.

Table 4. Relationship Between Demographic and Clinical Variables and the HADS Subscales Scores, $\mathbf{n = 6 5}$, Student's t-test

\begin{tabular}{|c|c|c|}
\hline Variable & Anxiety, mean (sd) & Depression, mean (sd) \\
\hline \hline Gender (M/F) & $5.2(4.0) / 7.7(3.6)(\mathrm{p}=.012)$ & $5.7(4.8) / 6.9(4.8)(\mathrm{p}=\mathrm{NS}) *$ \\
\hline Age & Pearson's=-.200 (p= NS) & $5.7(4.6) / 7.4(5.2)(\mathrm{p}=\mathrm{NS}) *$ \\
\hline Marital status (married/other) & $5.7(3.6) / .4(4.8)(\mathrm{p}=\mathrm{NS})$ & $5.0(4.3) / 7.0(5.0)(\mathrm{p}=\mathrm{NS}) *$ \\
\hline Employment (active/other) & $7.1(4.4) / 5.6(3.7)(\mathrm{p}=\mathrm{NS})$ & $8.7(5.0) / 5.2(4.4)(\mathrm{p}=.007)^{*}$ \\
\hline Psychiatric history $(\mathrm{Y} / \mathrm{N})$ & $10.0(4.1) / 4.7(2.9)(\mathrm{p}<.001)$ & $8.4(5.3) / 5.5(4.4)(\mathrm{p}=.030)^{*}$ \\
\hline Psychotropic drugs (Y/N) & $9.6(3.5) / 5.1(3.5)(\mathrm{p}<.001)$ & $8.6(4.8) / 5.1(4.4)(\mathrm{p}=.005)^{*}$ \\
\hline Alcohol intake $(\mathrm{Y} / \mathrm{N})$ & $6.9(3.6) / 5.9(4.2)(\mathrm{p}=\mathrm{NS})$ & \\
\hline
\end{tabular}

*Student's t-test.

Doctors assessed the presence or absence of somatic and psychiatric disorders in 45 of their patients $(69.2 \%)$, and considered that the majority $(48.8 \%)$ had just a somatic disease, followed by $42.2 \%$ having a somatic disease with psychiatric co-morbidity, and $8.8 \%$ having a psychiatric disorder with somatic co-morbidity. In those diagnosed with a psychiatric condition $17.8 \%$ were considered to have depressive disorders, followed by anxiety disorders, delirium and psychosis. Diagnosis was not clear in $6.7 \%$ of the patients assessed. The mean severity of the somatic and psychiatric diagnosis in a 1 to 5 scale was 3.3 and 3.0, respectively.

ICU nurses assessed the presence or absence of somatic and psychiatric disorders in 41 of the patients $(63.1 \%)$, and considered that the majority $(53.7 \%)$ presented a somatic disease with psychiatric co-morbidity, followed by $41.5 \%$ having just a somatic disease, and $4.9 \%$ having a psychiatric disorder with somatic co-morbidity. In those diagnosed with a psychiatric problem, $24.4 \%$ were considered to have a depressive disorder, $24 \%$ an anxiety disorder, and the remaining delirium. The mean severity of the somatic and psychiatric diagnosis was 3.4 and 2.8 , respectively.

ICU doctors' and nurses' detection of psychiatric disorders (all the patients considered to have a psychiatric disorder either primary or secondary) were compared with the CAGE results and the HADS scores (Table 6), and statistically significant relationships were found with the HADS anxiety scores for both professional groups ( $\mathrm{p}=.013$ for doctors, and $\mathrm{p}=.001$ for nurses), and with HADS depression scores for doctors $(\mathrm{p}=.046)$.

Severity of psychiatric disorder assessed by ICU doctors and nurses and the HADS scores were analyzed using Spearman's correlation (Table 7). There were significantly positive correlations between both doctors' and nurses' assessment of psychiatric disorder severity and anxiety scores on the HADS, and between doctors' assessment of the severity of psychiatric disorder and the HADS depression scores.

\section{DISCUSSION}

Our results confirm those of previous studies in the fact that depressive and anxiety symptoms are highly prevalent in patients admitted to intensive care units. In this sample of Gastroenterology ICU patients, $29 \%$ had a positive score in the HADS anxiety subscale and $35 \%$ in the depression subscale. These figures are higher than those obtained in previous studies: $24 \%$ for anxiety and $13.7 \%$ for depression in the study by Rincon et al. [4]. This difference can be explained by their inclusion of patients from different types of ICU, thus confirming our hypothesis of psychiatric morbidity higher rates in a GE ICU. It can also be related with their earlier assessment (first 24 hours).

As in other studies [4,7], the high rates of ICU depression and anxiety symptoms found in our study (27\% and $25 \%$ 
Table 5. Doctors' and Nurses' Assessment of Somatic and Psychiatric Disorders

\begin{tabular}{|c|c|c|}
\hline & Doctors (n=45) & Nurses (n=41) \\
\hline \hline Cause of disorder (\%) & & $17(41.5)$ \\
Somatic only & $22(48.8)$ & $22(53.7)$ \\
Somatic with psychiatric co-morbidity & $19(42.2)$ & $4(8.9)$ \\
Psychiatric with somatic co-morbidity & & $17(41.5)$ \\
\hline Psychiatric diagnosis (\%) & $22(48.8)$ & $10(24.4)$ \\
Absent & $8(17.8)$ & $10(24.4)$ \\
Depression & $7(15.6)$ & $4(9.7)$ \\
Anxiety & $4(8.9)$ & 0 \\
Delirium & $3(6.7)$ & 0 \\
Not clear & $1(2.2)$ & $3.4(0.7)$ \\
\hline Psychosis & $3.3(0.8)$ & $2.8(1.0)$ \\
\hline
\end{tabular}

Table 6. Comparison between ICU Doctors' and Nurses' Diagnosis and the CAGE and HADS Scores

\begin{tabular}{|c|c|c|c|c|c|c|}
\hline & \multicolumn{3}{|c|}{ ICU Doctors Diagnosis (n=45) } & \multicolumn{3}{c|}{ ICU Nurses Diagnosis (n=41) } \\
\hline & Psychiatric & Somatic & Significance & Psychiatric & Somatic & Significance \\
\hline \hline CAGE $(\%$ P / N)* & $76.9 / 63.5$ & $23.1 / 36.5$ & $\mathrm{p}=\mathrm{NS} * *$ & $92.3 / 69.2$ & $7.7 / 30.8$ & $\mathrm{p}=\mathrm{NS} * *$ \\
\hline HADS-A, mean (sd) & $8.6(4.2)$ & $4.5(3.2)$ & $\mathrm{p}=.013^{* * *}$ & $8.0 \pm 4.2$ & $4.1 \pm 2.2$ & $\mathrm{p}=.001 * * *$ \\
\hline HADS-D, mean (sd) & $8.1(5.4)$ & $5.2(4.1)$ & $\mathrm{p}=.046^{* * *}$ & $8.4 \pm 5.0$ & $5.5 \pm 4.2$ & $\mathrm{p}=.057^{* * *}$ \\
\hline
\end{tabular}

*CAGE (case percentages Positive / Negative); **Fisher's exact test; *** Student's t-test.

Table 7. Correlation Between ICU Doctors' and Nurses' Assessment of the Severity of Psychiatric Disorder and HADS Scores, Spearman's Correlation

\begin{tabular}{|c|c|c|c|c|}
\hline & \multicolumn{2}{|c|}{ Doctors' Severity Assessment (n=45) } & \multicolumn{2}{c|}{$\begin{array}{c}\text { Nurses' Severity Assessment } \\
(\mathbf{n}=\mathbf{4 1})\end{array}$} \\
\hline \hline HADS Anxiety & $\mathrm{rho}=.495$ & $\mathrm{p}=.001$ & $\mathrm{rho}=.541$ & $\mathrm{p}<.001$ \\
\hline HADS Depression & $\mathrm{rho}=.314$ & $\mathrm{p}=.036$ & $\mathrm{rho}=.201$ & $\mathrm{p}=.208$ \\
\hline
\end{tabular}

respectively) were associated with a past psychiatric history and previous medication with psychotropic drugs. Patients with a psychiatric history had a 7.4 times greater risk of developing higher psychological distress (HADS total score) when admitted to ICU, while being on psychotropic drugs resulted in an increased risk of only 2.4 times.

Alcohol intake was expected to be high in this gastroenterology ICU sample, and the obtained rate of $32 \%$ of patients with intake above standard, and of $20 \%$ positive CAGE tests are in accordance with figures from mentioned studies $[12,13,14,17]-24-28 \%$ in ICUs, and $44-51 \%$ in gastroenterology departments. CAGE scores were significantly higher in men, as expected. The sensitivity of the CAGE test $(52 \%)$ was lower in this sample than the expected value of $71 \%$; however, the specificity $(95 \%)$ was higher than the expected value of $90 \%$ [19]. The high cut-offs used for stan- dard intake levels (40g for females and $80 \mathrm{~g}$ for males) may explain these differences.

Compared to men, women presented significantly higher anxiety scores on the HADS but they did not differ in the HADS depression scores, contrary to the fact that women are usually more depressed than men in most studies. This result may be explained by higher levels of depression being associated with alcohol intake above standard in our sample, and by men's higher alcohol intake. The significant association of high alcohol intake and depression (but not anxiety) scores found in this study confirms the well-established relationship between alcohol abuse and dependence, and depression [20].

Detection of psychiatric disorders by the ICU staff was significantly associated with anxiety scores, as depression or 
alcohol abuse were not diagnosed. Although surprising, this result is not unexpected: anxiety symptoms can be more apparent in daily contacts with the patients, and are more frequently communicated, being more socially accepted and less stigmatizing than other symptoms. However, the number of patients not assessed by the staff, and related with rotation and shift work, can limit the reliability of these results.

The significant positive correlation found between ICU professionals' detection of severity of psychiatric disorders and anxiety and depression scores is a good indicator of the ability of these professionals to detect the most severe situations and refer them for psychiatric evaluation. These results are more favorable than those referred by Rincon et al. [4] in a coronary ICU, where there was no association between ICU doctors' detection and the HADS scores.

The current study has several main limitations. The fact that no formal psychiatric diagnosis was established and the use of a rating scale may have led to an overestimation in the results. Although severe cognitive impairment was an exclusion criterion, non-systematic ruling out of milder forms could have the same effect. Finally, the small size of the sample, due to the exclusion of many patients, led to overfitting problems shown by the large confidence intervals.

Future research of psychiatric morbidity in ICU should address these limitations. The probability that large numbers of ICU inpatients are unable to collaborate in a psychiatric assessment can recommend the use of information provided by family members.

\section{ACKNOWLEDGEMENT}

We want to thank José Caldas de Almeida, Miguel Xavier and Miguel Almedia for their review of the manuscript, and Ana Papoila for her valuable help with the statistical analysis.

\section{REFERENCES}

[1] Mayou R, Hawton K. Psychiatric disorder in the general hospital. Br J Psychiatry 1986; 149: 172-90.

[2] Nair MG, Pillay SS. Psychiatric disorder in a South African general hospital. Prevalence in medical, surgical, and gynecological wards. Gen Hosp Psychiatry 1997; 19: 144-8.

[3] Hansen MS, Fink P, Frydenberg M, Oxhøj M, Søndergaard L, Munk-Jørgensen P. Mental disorders among internal medical inpa- tients: Prevalence, detection, and treatment status. J Psychosom Res 2001; 50: 199-204.

[4] Rincon HG, Granados M, Unutzer J, Gomez M, Duran R, Badiel M, Salas C, Martinez J, Mejia J, Ordoñez C, Florez N, Rosso F, Echeverri P. Prevalence, detection and treatment of anxiety, depression, and delirium in the adult critical care unit. Psychosomatics 2001; 42: 391-6.

[5] Girard TD, Pandharipande PP, Ely EW. Delirium in the intensive care unit. Crit Care 2008; 12 Suppl 3: S3.

[6] Roberts B. Screening for delirium in an adult intensive care unit. Intensive Crit Care Nursing 2004; 20: 206-13.

[7] Weinert C, Meller W. Epidemiology of depression and antidepressant therapy after acute respiratory failure. Psychosomatics 2006; 47(5): 399-407.

[8] Sukantarat K, Greer S, Brett S, Williamson R. Physical and psychological sequelae of critical illness. Br J Health Psychol 2007; 12(Pt 1): 65-74.

[9] Delgado-Rodriguez M, Gomez-Ortega A, Mariscal-Ortiz M, Palma-Perez S, Sillero-Arenas M. Alcohol drinking as a predictor of intensive care and hospital mortality in general surgery: a prospective study. Addiction 2003; 98: 611-6.

[10] Marik P, Mohedin B. Alcohol-related admissions to an inner city hospital ICU. Alcohol Alcohol 1996; 31(40): 393-6.

[11] Uusaro A, Parviainen I, Tenhunen JJ, Ruokonen E. The proportion of intensive care unit admissions related to alcohol use: a prospective cohort study. Acta Anaesthesiol Scand 2005; 49: 1236-40.

[12] Mostafa SM, Murthy BV. Alcohol-associated admissions to an adult intensive care unit: an audit. Eur J Anaesthesiol 2002; 19: 193-6.

[13] Waddell TS, Hislop WS. Analysis of alcohol-related admissions in gastroenterology, cardiology and respiratory medicine. Scott Med J 2003; 48: 114-6.

[14] Hislop WS, Heading RC. Impact of alcohol related disease and inpatient workload of gastroenterologists in Scotland. Scott Med J 2004; 49: 57-60.

[15] Barth J, Schumacher M, Hermann-Lingen C. Depression as a risk factor for mortality in patients with coronary heart disease: a metaanalysis. Psychosom Med 2004; 66(6): 802-13.

[16] Moser DK, Dracup K. Is anxiety after MI associated with subsequent ischemic arrhythmic events? Psychosom Med 1996; 58(5): 395-401.

[17] Zigmond AS, Snaith RP. The Hospital Anxiety and Depression Scale. Acta Psychiatr Scand 1983; 67: 361-370.

[18] Ewing, JA. Detecting alcoholism. The CAGE questionnaire. JAMA 1984; 252: 1905-7.

[19] Dhalla S, Kopec JA. The CAGE questionnaire for alcohol misuse: a review of reliability and validity studies. Clin Invest Med 2007; 30: 33-41.

[20] Davis L, Uezato A, Newell JM, Frazier E. Major depression and comorbid substance use disorders. Curr Opin Psychiatry 2008; 21: 14-8.

Received: December 30, 2009

Revised: March 25, 2010

Accepted: May 13, 2010

(C) Cardoso et al.; Licensee Bentham Open.

This is an open access article licensed under the terms of the Creative Commons Attribution Non-Commercial License (http://creativecommons.org/licenses/by-nc/3.0/) which permits unrestricted, non-commercial use, distribution and reproduction in any medium, provided the work is properly cited. 